\title{
Multislice Angio Computed Tomography in the Diagnosis of Cardiovascular Diseases
}

\author{
Monica Chițu
}

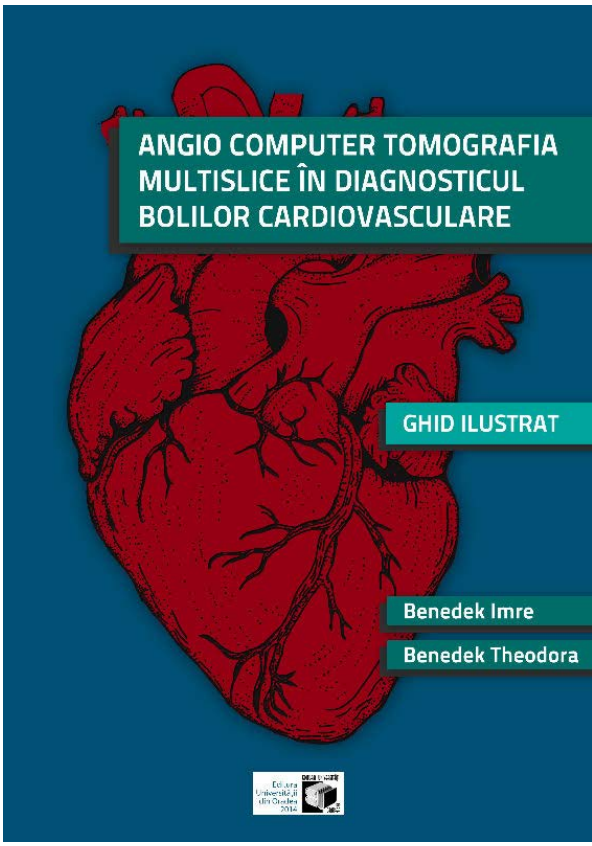

Book title

Angio Computer Tomografia Multislice în Diagnosticul Bolilor Cardiovasculare

\section{Authors}

Imre Benedek, Theodora Benedek
The book entitled "Multislice Angio Computed Tomography in the Diagnosis of Cardiovascular Diseases" (original title "Angio Computer Tomografia Multislice în Diagnosticul Bolilor Cardiovasculare") represents a comprehensive overview on different applications of this new imaging method in a large variety of cardiovascular applications. Being illustrated with an impressive number of images from the large own casuistry of the authors, the book represents an extremely useful tool for many medical practitioners active in the field of cardiovascular diseases or related disciplines (cardiologists, radiologists, internal medicine, general practitioners, etc), at different levels (medical students, residents, specialists or senior physicians).

The book is structured in 15 chapters, each dedicated to a specific cardiovascular pathology. What is particularly useful in this book is the integration of the clinical pictures related to several pathologies with the presentation of the results of large clinical trials addressing those pathologies. This complex integration of all related data make this book an extremely helpful instrument for those who aim to learn the applications and the limits of the new techniques presented.

The addressed pathology is extremely complex, including coronary artery diseases, peripheral arterial diseases, congenital heart diseases, aortic and cerebrovascular diseases, myocardial bridges, follow-up of patients with coronary stents or patients undergoing bypass surgery, and also particular applications dedicated to the role of Cardio CT in assisting interventional procedures.

One of the most challenging aspects addressed in the book is dedicated to the research of vulnerable coronary plaques using Cardio CTderived tools, a field in which the authors present a very relevant expertise and many achievements.

All these aspects make the book extremely attractive and an extremely useful learning tool for all those who intend to acquire new knowledge regarding Cardio CT, a new methodology that is starting to be used more and more in different interdisciplinary medical sectors. 